\title{
LEVANTAMENTO DE MANIFESTACÕES PATOLÓGICAS EM EDIFICAÇ̃̃O ESCOLAR - ESCOLA TÉCNICA CENECISTA PROF. DURBAN FERRAZ FERREIRA EM TORRES / RS
}

\author{
LOPES LARROSA, GABRIEL \\ Engenheiro civil \\ Faculdade de Tecnologia TecBrasil - FTEC \\ Rio Grande do Sul; Brasil \\ lopeslarrosa@gmail.com
}

\author{
REIS ANTUNES, GISELLE \\ Engenheira Civil \\ Faculdade de Tecnologia TecBrasil - FTEC e \\ Universidade Federal do Rio Grande do Sul \\ Rio Grande do Sul; Brasil \\ engcivil.giselle@gmail.com
}

\section{RESUMO}

Os edifícios têm um ciclo de vida útil, porém existem fatores que podem prolongar este tempo e colaborar para melhor durabilidade destas. Entre estes fatores ressalta-se o bom desenvolvimento do projeto; o sucesso do planejamento e condições de trabalho durante a construção, envolvendo a qualidade dos materiais e mão de obra; a consideração das condições do meio em que a obra está inserida; a realização de inspeções prediais regulares e manutenções periódicas. Sabendo-se que, nacionalmente, os prédios públicos passam por poucas manutenções, por razões políticas e/ou orçamentárias neste trabalho procurou-se identificar as principais manifestações patológicas, por fachada e por componentes construtivos, incidentes na Escola Técnica Cenecista Durban Ferraz Ferreira em Torres / RS, adotando-se mapas de danos e fichas de identificação de danos (FID) para apuração das causas e método de GUT para definição da ordem de prioridades de intervenção de reparo. A interpretação analítica dos resultados permitiu obter o diagnóstico e verificar que a maioria das manifestações patológicas provém principalmente do vandalismo, falha de estanqueidade, corrosão, agravados pela falta de manutenção e ação agressiva do meio ambiente. De forma geral para uma edificação pública abandonada, sem rotinas de manutenção preventiva e corretiva, especialmente exposta a condições de agressividade intensas como neste objeto de estudo, exposta ao ambiente marinho, estão mais sujeitas a alta incidência de manifestações patológicas e com o abandono estas podem evoluir levando a um possível colapso da edificação.

Palavras-chave: manifestações patológicas, prédio público, ambiente agresssivo, diagnóstico.

\section{ABSTRACT}

Buildings have a life cycle, but there are factors that can extend this time and collaborate for better durability of these. Among these factors is the good development of the project; the success of planning and working conditions during construction, involving the quality of materials and labor; the consideration of the conditions of the environment in which the work is inserted; regular building inspections and periodic maintenance. Nationally, public buildings usually undergo little maintenance, either for political and / or budgetary reasons. In this work we sought to identify the main anomalies, by façade and building components, incident at the Technical School Cenecista Durban Ferraz Ferreira in Torres / RS. Damage maps and damage identification sheets (FID) were adopted to determine the causes and GUT method to define the order of repair intervention priorities. The analytical interpretation of the results allowed to obtain the diagnosis and verify that the majority of the anomalies come mainly from vandalism, lack of sealing, corrosion, aggravated by the lack of maintenance and aggressive action of the environment. In general, for an abandoned public building, without preventive and corrective maintenance routines especially exposed to intense aggressive conditions as in this object of study, exposed to the marine environment, are more subject to a high incidence of anomalies and with the abandonment these can evolve leading to a possible collapse of the building.

Keywords: anomalies, public building, aggressive environment, diagnosis.

\section{INTRODUÇÃO}

O presente estudo de caso baseia-se em uma inspeção predial, em edificação escolar (figura 1) construída no ano de 1940, localizada em um dos principais pontos turísticos da cidade de Torres no Rio Grande do Sul, no Morro do Farol, exatamente na Rua Alferes Francisco Porto, SN, Bairro Centro, CEP 95560-000.

Esta edificação possui um contexto histórico e cultural relevante para Torres, visto que foi a primeira escola construída na cidade. Na época da construção, o Morro do Farol foi escolhido por ser um local centralizado na cidade, que pudesse acolher o maior número possível de alunos, de forma confortável, com espaço para atividades físicas e escolares. A sua localização privilegiada, estimulou o crescimento da cidade, pois fica em uma das suas cinco principais ruas, e tornouse um marco para o desenvolvimento local que na época recebia educação na paróquia municipal. 


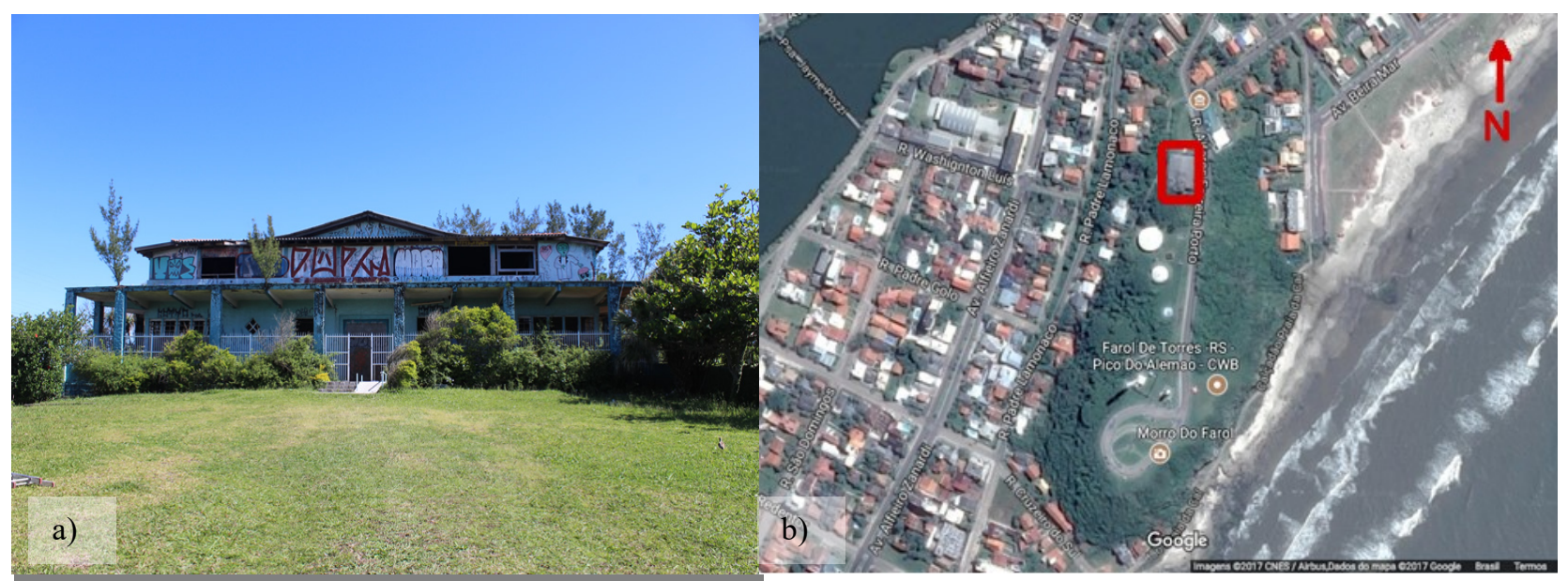

Figura 1: a) Edificação b) Imagem de satélite da edificação em estudo (Google Maps)

No ano de 1980, o prédio localizado no Morro do Farol, onde funcionara a Escola Estadual Marcílio Dias, foi cedido ao então Colégio Comercial de Torres, pela Prefeitura do mesmo município. Neste período iniciou o ano letivo da Escola Cenecista de $2^{\circ}$ Grau de Torres. Embora o prédio fosse municipal a escola era mantida com recursos particulares provenientes dos pais de alunos, bolsas integrais disponibilizadas pelo estado e bolsas parciais fornecidas pela Prefeitura Municipal. No ano de 1995, o Conselho Comunitário da época decidiu realizar uma homenagem ao primeiro diretor da escola, então a escola passou a chamar-se Escola Cenecista de $2^{\circ}$ Grau Professor Durban Ferraz Ferreira. Na década de 1990, o segundo pavimento da edificação sofreu uma intervenção técnica, onde foi ampliado o espaço tornando um grande salão para 200 pessoas, que na época funcionara como uma casa de eventos para angariar fundos para a escola. No dia 14 de fevereiro de 2011 a fundação que administrava a Escola anunciou a interdição e o cancelamento das atividades educacionais desenvolvidas há mais de 31 anos naquele prédio, por conta de razões financeiras e políticas. O poder público cortou as bolsas fornecidas e aumentou as vagas nas escolas públicas locais.

Atualmente a escola é uma das únicas edificações históricas da cidade, com potencial turístico que se encontra desperdiçado, pois encontra-se abandonada há 6 anos, sujeita a depredações e invasões, com rumores de sua demolição. Embora esteja situada num lugar de natureza exuberante, com uma linda vista da cidade, o prédio está submetido a um ambiente altamente agressivo, por conta da exposição aos agentes biológicos e climáticos do litoral. Edificações neste tipo de contexto exigem uma atenção especial durante o desenvolvimento de seus projetos e manutenções. Durante o levantamento de dados da edificação em estudo, que desde a sua fundação foi de uso Escolar, não foram encontrados muitos registros de manutenção, reformas, nem documentos da época da construção como projetos arquitetônicos, estruturais e de instalações, nem registros de diários de obra ou procedimentos executivos. O único documento obtido nos arquivos da Escola foi um Parecer Técnico emitido em outubro de 1991, com responsabilidade técnica do Arquiteto João Villanova Gallardo (CREA 52.100). O parecer visou avaliar a viabilidade de construção de um auditório no segundo pavimento com capacidade para 200 pessoas. O documento identificou um abandono nítido das edificações que faziam parte da escola, evidenciada pela vegetação densa e descuidada, focos de insetos e pequenos repteis concluindo a necessidade da desocupação do prédio 1 que se encontrava habitado por uma família. Para os demais esclarecimentos construtivos não foram localizados documentos que as evidenciem.

Este trabalho tem como objetivo geral fazer levantamento das manifestações patológicas, realizar o dignóstico com classificação das manifestações patológicas quanto ao grau de risco de modo auxiliar na determinação das prioridades para a execução de recuperação do prédio.

\section{REVISÃO BIBLIOGRÁFICA}

A norma ASTM E632-82 (1996) define "fator de degradação como qualquer fator externo que afete de maneira desfavorável o desempenho de um edifício ou de suas partes, incluindo nisto as intempéries, agentes biológicos, esforços, incompatibilidade e fatores de uso". A própria norma alerta que esta lista não é exaustiva e outros possíveis fatores importantes deveriam ser verificados em cada caso específico.

O edifício, num determinado contexto, está sujeito às condições do ambiente, mais ou menos variáveis, recebendo influências de naturezas diversas ao longo do tempo. A norma ASTM E632-82 (1996) define fatores ambientais como 
"todos os grupos de fatores associados com o ambiente natural, incluindo radiação, temperatura, chuva e outras formas de água, gelo e degelo, constituintes normais do ar e seus poluentes e vento".

O meio ambiente onde as estruturas podem ser inseridas são classificadas, de acordo com o grau de agressividade da atmosfera do mesmo, em atmosfera rural, atmosfera urbana, atmosfera marinha e atmosfera industrial.

Segundo Fortes (1995) e Lersh (2003), o clima exerce grande influencia no surgimento das manifestações patológicas:

- Nos climas quentes e secos, com grande amplitude térmica diária, um dos principais fatores de degradação é a temperatura do ar. Esta afeta a plasticidade e a capacidade física de contração e expansão dos materiais, ocasionando descontinuidade, principalmente nas superfícies e revestimentos.

- Nos climas frios, os problemas mais graves que podem ocorrer são a condensação do vapor d'água sobre os materiais e o congelamento d'água presente nas alvenarias e nas tubulações.

- $\quad \mathrm{Na}$ atmosfera rural, região de ar livre, caracterizada pela baixa taxa de poluentes, com fraca agressividade às armaduras do concreto. Nesse meio, os teores de íons e gases agressivos se tornam desprezíveis, inclusive os teores de $\mathrm{CO}_{2}$.

- $\quad \mathrm{Na}$ atmosfera urbana os teores íons e gases agressivos não são desprezíveis, uma vez que são regiões localizadas nos centros de maior população contem impurezas como óxidos de enxofre, fuligem ácida e outros agentes agressivos. As partículas ácidas em suspensão contribuem para o desencadeamento da corrosão das armaduras de concreto pelo fato de acumular água na superfície.

- Nas regiões sobre o mar ou próximas da orla marítima a agressividade do meio é devido à umidade relativa do ar, cloretos de sódio e magnésio. Esses agentes são extremamente agressivos e aumentam a velocidade de corrosão na ordem de 30 a 40 vezes em relação à que ocorreria no ambiente rural.

A figura 2, estruturada por Lersh (2003), apresenta as principais causas de deterioração das edificações, dividindo-as

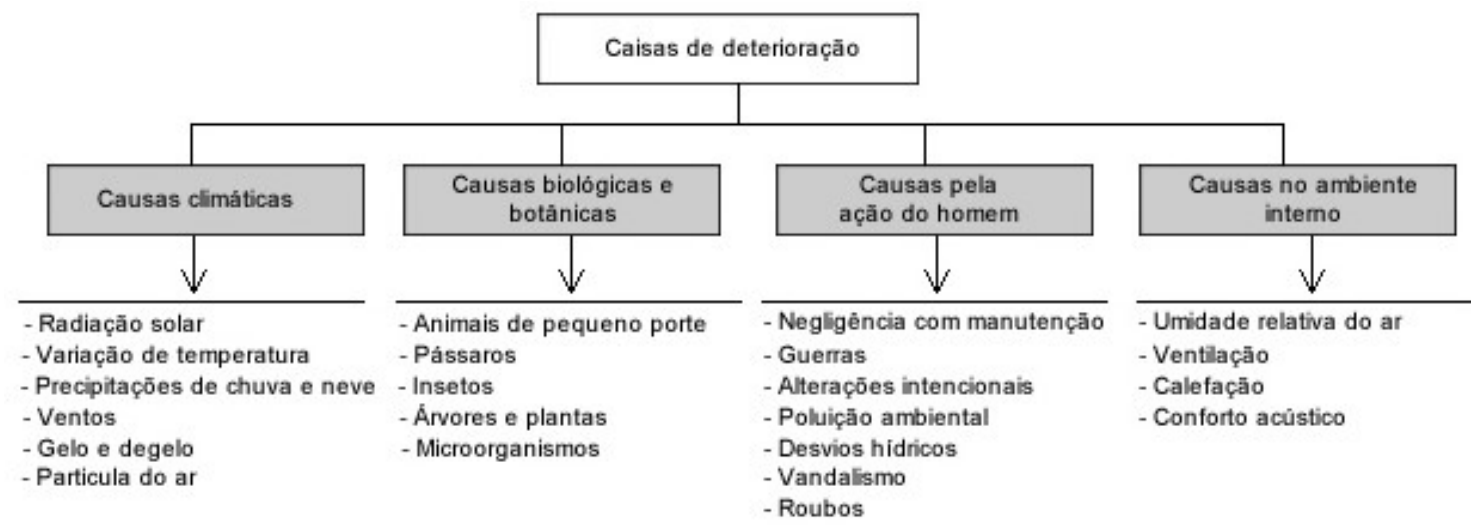

por: climáticas, biológicas, naturais e de uso da edificação, exemplificando cada ação causal.

Figura 2: Principais causas de deterioração das edificações (Adaptada de Lersh, 2003)

Conforme defendido por Neumann (2017) a durabilidade implica na estabilidade e resistência a agentes físicos, químicos e biológicos, oriundos de causas naturais ou artificiais. Os requisitos de higiene visam à saúde e ao bem-estar do usuário da construção. O fator estético é observado quanto ao aspecto do material colocado, de cujo emprego simples ou combinado, se pode tirar partido para a beleza da obra.

Para a análise isolada ou combinada das condições técnicas, de uso e de manutenção da edificação é necessário a observância das normas pertinentes e de metodologias utilizadas por autores da área. Assim, forma-se um conjunto de ferramentas que orientam a realização da inspeção predial.

Na tabela 1 apresenta-se de forma resumida a metodologia de inspeção predial de Pacheco (2017), Tomazeli (2017) e Antunes (2010), que apesar de terem projetos independentes e em diferentes áreas, tem uma padronização no método de inspeção quanto às técnicas de investigação, diagnóstico e exposição dos dados.

Por outro lado, para definir as prioridades de intervenções de reparo numa edificação acometida por manifestações patológicas, Kepner e Tregoe (1981) desenvolveram a ferramenta conhecida por método GUT (Gravidade, Urgência e Tendência). Esta ferramenta consiste em analisar a gravidade ou o impacto do problema nas operações e pessoas 
envolvidas, a urgência ou a brevidade necessária para a resolução dos problemas e a tendência ou apresentação de melhora ou piora do problema. Ele se utiliza de três escalas (colunas de decisão) para definir uma prioridade, e através da combinação delas é possível fazer uma priorização eficaz, orientando a tomada de decisão e a resolução de problemas. É necessário que cada problema a ser analisado receba um valor ponderador (1-nenhuma, 3-baixa, 6-média, 8-alta ou 10-total) considerando cada uma das características: gravidade, urgência e tendência

Tabela 1 - Comparativo entre metodologias de coleta de dados

\begin{tabular}{|c|c|c|c|}
\hline Etapa & Pacheco (2017) & Tomazeli (2017) & Antunes (2010) \\
\hline $\begin{array}{l}\text { Levantamento } \\
\text { de dados }\end{array}$ & $\begin{array}{l}\text { Enfatiza a importância da visita } \\
\text { inicial, levantamento dos } \\
\text { principais problemas aparentes } \\
\text { com uma prévia elaboração de } \\
\text { croqui e mapeamento. }\end{array}$ & $\begin{array}{l}\text { As estruturas de devem ser } \\
\text { inspecionadas nos seus mais } \\
\text { diversos aspectos. }\end{array}$ & $\begin{array}{l}\text { Vistoria de aspecto geral no sentido de } \\
\text { coletar o máximo de informações } \\
\text { possíveis sobre o edifício a ser } \\
\text { estudado. }\end{array}$ \\
\hline $\begin{array}{l}\text { Mapeamento } \\
\text { Inicial das } \\
\text { Manifestações } \\
\text { Patológicas }\end{array}$ & $\begin{array}{l}\text { Identifica os mecanismos de } \\
\text { envelhecimento e deterioração. } \\
\text { Determinar a agressividade do } \\
\text { meio ambiente }\end{array}$ & $\begin{array}{l}\text { Define o nível de } \\
\text { degradação. } \\
\text { Identifica os locais de maior } \\
\text { incidência de manifestações } \\
\text { patológicas. }\end{array}$ & $\begin{array}{l}\text { Adota uma sistemática que organize o } \\
\text { mapeamento e levantamento, } \\
\text { subdividindo por pavimentos, } \\
\text { orientações e demais dados que tornem } \\
\text { a inspeção eficaz e organizada. }\end{array}$ \\
\hline $\begin{array}{l}\text { Quantificação } \\
\text { e Qualificação } \\
\text { das } \\
\text { Manifestações } \\
\text { Patológicas }\end{array}$ & $\begin{array}{l}\text { Pré defini os croquis das } \\
\text { ocorrências das manifestações } \\
\text { patológicas, realiza todos os } \\
\text { aspectos quantitativos através } \\
\text { de ensaios. }\end{array}$ & $\begin{array}{l}\text { Estabelece uma ordem de } \\
\text { grau de deterioração } \\
\text { variando de } 1 \text { (sem } \\
\text { degradação) a } 10 \text { (elevado } \\
\text { nível de degradação). }\end{array}$ & $\begin{array}{l}\text { Identifica a ocorrência dos danos } \\
\text { encontrados e estabelecem-se níveis de } \\
\text { degradação com valor atribuído } \\
\text { variando de } 0 \text { (sem degradação) a } 4 \\
\text { (elevado nível de degradação). }\end{array}$ \\
\hline $\begin{array}{l}\text { Exposição dos } \\
\text { Dados } \\
\text { Analisados }\end{array}$ & $\begin{array}{l}\text { São registradas as resistências } \\
\text { estimadas dos valores obtidos }\end{array}$ & $\begin{array}{l}\text { Se baseia em ferramentas de } \\
\text { Gestão da Qualidade como } \\
\text { sugere a Norma de Inspeção } \\
\text { Predial do IBAPE. }\end{array}$ & $\begin{array}{l}\text { Elabora matrizes de correlação e } \\
\text { elaboração de Gráficos para facilitação } \\
\text { das análises. }\end{array}$ \\
\hline $\begin{array}{l}\text { Resultado e } \\
\text { Finalização da } \\
\text { Inspeção } \\
\text { Predial }\end{array}$ & $\begin{array}{l}\text { Propõe atitudes a serem } \\
\text { adotadas para sua recuperação. } \\
\text { Recomenda um plano de } \\
\text { manutenção preventiva }\end{array}$ & $\begin{array}{l}\text { Propõe atitudes a serem } \\
\text { adotadas para sua } \\
\text { recuperação. } \\
\text { Recomenda um plano de } \\
\text { manutenção preventiva }\end{array}$ & $\begin{array}{l}\text { Propõe atitudes a serem adotadas para } \\
\text { sua recuperação. } \\
\text { Recomenda um plano de manutenção } \\
\text { preventiva }\end{array}$ \\
\hline
\end{tabular}

Os pesos para os parâmetros da escala Gravidade, Urgência e Tendência atribuídos a cada problema são multiplicados, dando origem a um valor resultante. Ao final a pontuação mostrará o grau de prioridade de tratamento dos problemas (GUT).

\section{ESTUDO DE CASO}

A edificação estudada na presente pesquisa trata-se de um prédio com $2.170 \mathrm{~m}^{2}$ de área, divididos em dois pavimentos distribuídos na seguinte forma:

- Pavimento 1: com o total de $1.085 \mathrm{~m}^{2}$, composto de oito salas de aula, três banheiros, três escritórios, uma cozinha, um hall de entrada, um salão principal, um salão secundário, e uma varanda no entorno do prédio.

- Pavimento 2: com o total de $1.085 \mathrm{~m}^{2}$, composto de uma cozinha, dois banheiros, um hall de entrada e um salão de eventos para 200 pessoas.

- Cobertura: possui estrutura do telhado composta por tesouras de madeira e telhamento em telhas de fibrocimento.

A edificação apresenta como sistema construtivo, pilares, vigas e lajes em concreto armado; alvenaria em tijolo cerâmico maciço; cobertura estrutura de madeira e telhamento em telha de fibrocimento; acabamento das paredes em pintura e dos pisos em revestimento cerâmico. Levando-se em conta os procedimentos gerais para avaliação de bens imóveis urbanos indicados pela norma NBR 14653-2 (ABNT, 2011) tem-se para o imóvel em estudo:

- Uso: Institucional

- Tipo: Escola

- Agrupamento: Loteamento 
- Finalidade: Escola de pequeno porte.

- Aspectos gerais da região: localizado em um dos principais pontos turísticos da cidade (Morro do Farol), no bairro Centro, região de alto poder econômico, seu terreno é o limite do loteamento residencial com a área de preservação ambiental, nas suas proximidades localiza-se comércios em geral como hotéis, pousadas, farmácias, posto de gasolina, restaurantes e praças.

- Aspectos físicos da região: localizado em região litorânea num contexto urbano na extremidade de uma reserva ambiental, com vegetação nativa aos fundos do prédio, construída sobre um Morro de Basalto.

- Ocupação e uso do solo na região: conforme plano diretor atual não é permitido construções nesta região, sendo autorizada somente a execução de reformas, de recuperação ou restauração das edificações existentes.

- Atividades existentes na região: comércio varejista, restaurantes, imobiliárias, hotéis, pousadas, bancos, farmácias e posto de gasolina.

- Equipamentos comunitários na região: Parque da Guarita, Igreja Católica (primeira igreja da cidade), praças, escolas, shoppings e praia.

\subsection{Metodologia aplicada}

Para elaboração da metodologia aplicada nesta pesquisa, que analisa o prédio da Escola Técnica Cenecista Prof. Durban Ferraz Ferreira adotaram-se como principais referencias os autores TOMAZELI, A.; HELENE, P. (2017), PACHECO, C.; VIEIRA, G. (2017), ANTUNES; G. (2010), TINOCO; J. (2009) e em conformidade com os parâmetros e critérios exigidos nas normas vigentes. No fluxograma apresentado na figura 3 observa-se de forma resumida as etapas contempladas para realização deste trabalho, detalhando sua manipulação e exposição dos dados coletados e obtidos na inspeção.

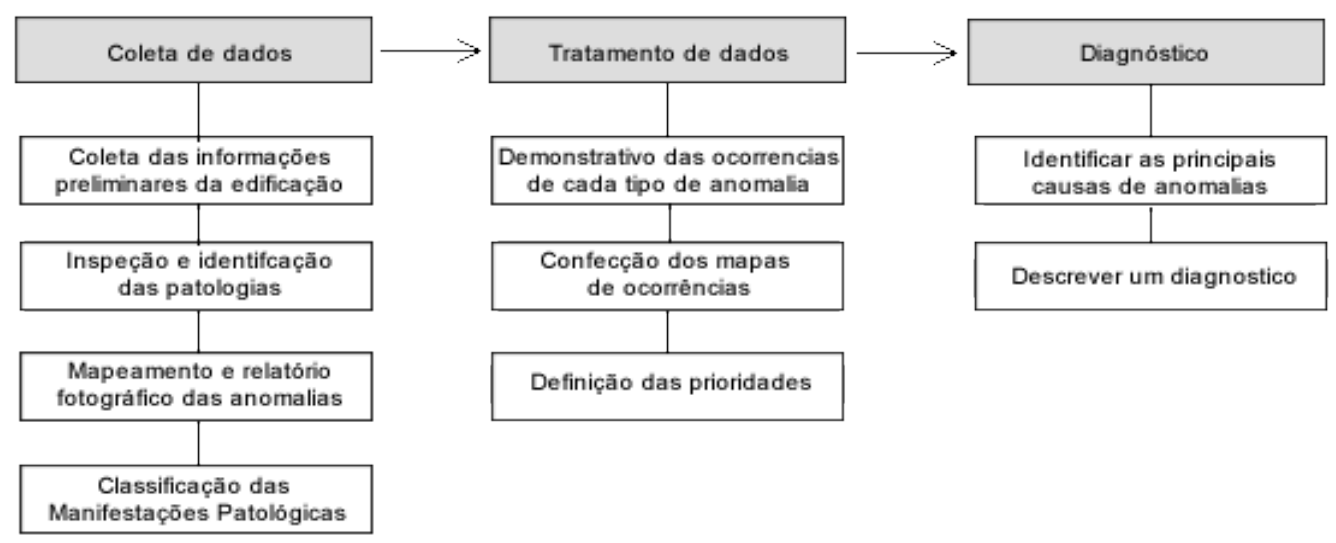

Figura 3: Estrutura da metodologia utilizada na inspeção predial deste trabalho

Na primeira etapa deste trabalho, procedeu-se com a coleta de documentação e informações do edifício objeto de estudo junto a própria administração da escola, na prefeitura e na paróquia da cidade de Torres/RS. Destaca-se que a edificação apresenta como sistema construtivo, pilares, vigas e lajes em concreto armado; alvenaria em tijolo cerâmico maciço; cobertura estrutura de madeira e telhamento em telha de fibrocimento. Acabamento das paredes em pintura e dos pisos em revestimento cerâmico. Considerando a classificação da inspeção segundo o IBAPE NACIONAL (2012), classificou-se a presente inspeção como nível 1. Definida pela norma como aquela realizada em edificações com baixa complexidade técnica, de manutenção e de operação de seus elementos e sistemas construtivos. Normalmente empregada em edificações com planos de manutenção muito simples ou inexistentes. A Inspeção Predial nesse nível é elaborada por profissionais habilitados em uma especialidade.

$\mathrm{Na}$ visita preliminar à edificação foi possível identificar a orientação cardeal das fachadas da edificação, vizinhança, limites do terreno e permitiu o levantamento de medidas para a elaboração do As built de plantas e fachadas, detalhes arquitetônicos. Nela também se buscou verificar a dimensão da inspeção e, detectar as principais manifestações patológicas manifestadas. Previamente o tratamento das informações coletadas procedeu-se com a divisão das manifestações patológicas em grupos, que seriam: manchas d'água, bolor e mofo, eflorescência, fissura, vegetação (trepadeiras e mudas de plantas), vandalismo (pichações e elementos danificados), corrosão, desplacamento e falhas de rejunte. Cada grupo representa o tipo de manifestação patológica observada nas visitas. A partir do Mapeamento de Danos criou-se uma legenda das principais manifestações patológicas da edificação em eudo, conforme figura 4. 


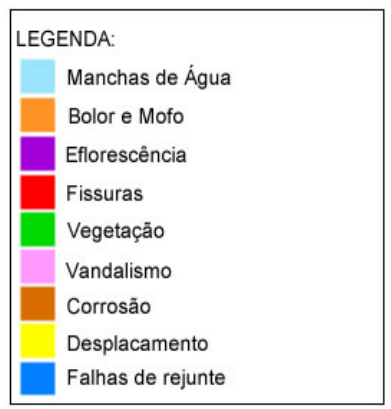

Figura 4: Legenda do mapa de danos

Em posse do as built das plantas e croquis da edificação e através do auxílio do Guia Técnico de Manifestações Patológicas (ANTUNES, 2010) procedeu-se com o registro das manifestações patológicas visíveis em um Mapa de Danos. Esta etapa ocorreu em 3 (três) visitas ao prédio. Para sistematização das inspeções, adotou-se uma ordem de avaliação no sentido horário, registrando-se as manifestações patológicas em todas as fachadas da edificação iniciando pela fachada norte, passando para leste, sul e finalizando em oeste. As manifestações patológicas visíveis foram registradas, simultaneamente, quantificadas e classificadas através de Fichas de Identificação de Danos - FID's. A FID adotada neste trabalho, conforme tabela 2, foi elaborada para a obtenção da base de dados e facilitar o diagnóstico. Para facilitar a elaboração das FID's, bem como a interpretação dos resultados cada fachada foi dividida em 3 prumadas. (três prumadas).

Tabela 2 - Ficha de identificação de danos

\begin{tabular}{|c|c|c|c|}
\hline \multicolumn{3}{|c|}{ FICHA DEIDENTIFICAÇÃO DE DANOS } & 01 \\
\hline Local & \multicolumn{3}{|c|}{$\begin{array}{l}\text { Morro do Farol, Rua Alferes Francisco Porto, SN, Bairro Centro, Torres, Rio } \\
\text { Grande do Sul }\end{array}$} \\
\hline \multicolumn{4}{|c|}{ Responsável pela vistoria } \\
\hline Auxiliares & & Data da vistoria & \\
\hline Item de inspeção & & Prumada & \\
\hline \multicolumn{4}{|l|}{ Descrição } \\
\hline \multicolumn{4}{|l|}{ Diagnóstico } \\
\hline Gravidade & Urgência & Tendência & GUT \\
\hline \multicolumn{4}{|l|}{ Tratamento } \\
\hline \multicolumn{4}{|c|}{ Registros fotográficos } \\
\hline
\end{tabular}

Em todas as prumadas das fachadas realizou-se o preenchimento das FIDs, com registros fotográficos e avaliação de componentes da edificação como: pilares, lajes, vigas, muro, paredes de alvenaria além de aberturas (portas, janelas e basculantes). Este procedimento permitiu a quantificação e qualificação das manifestações patológicas encontradas Uma vez que as manifestações patológicas se apresentam sob variadas urgências, gravidades e tendências, estas foram catalogadas de acordo com os grupos definidos, e a elas atribuídas pontuações conforme previu o método GUT (KEPNER e TREGOE, 1981). A prioridade para intervenções dos elementos e fachadas da edificação foram baseadas no mesmo método.

\subsection{Apresentação e análise dos resultados}

Neste item estão apresentados os mapas de danos resultantes de todas as fachadas bem como os resultados obtidos a partir da aplicação da ferramenta de GUT e dados extraídos nas FID’s.

\subsubsection{Fachada norte}

A fachada norte foi dividida em 3 prumadas e seus elementos construtivos avaliados e destacados conforme a figura 5. Para melhor compreensão das manifestações patológicas levantadas em campo e incidentes na fachada norte da edificação adotou-se o mapa de danos, conforme ilustra a figura 6. Sabendo-se que na fachada havia áreas cobertas por varanda, as manifestações patológicas identificadas nestas foram representadas em planta. 


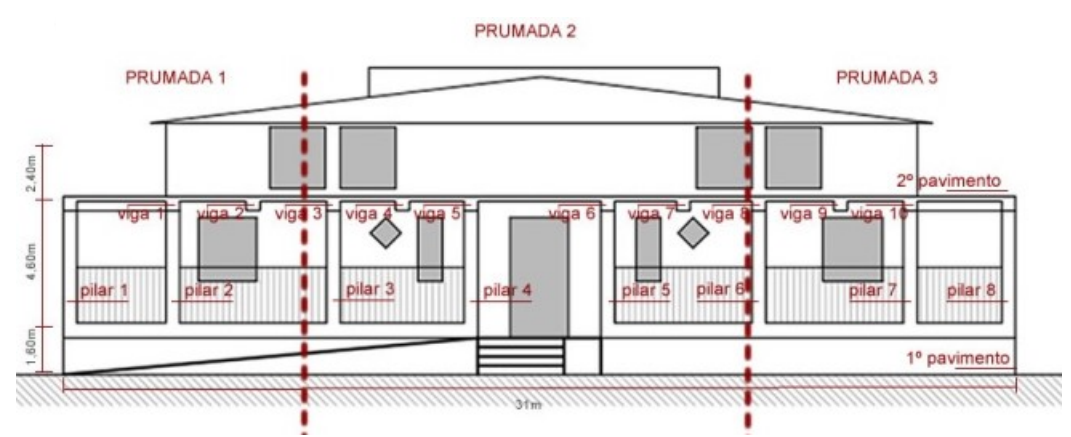

Figura 5: Fachada norte, dividida em 3 prumadas

Conforme a figura 6 nota-se que a manifestação patológica com maior área de abrangência na fachada norte se trata do vandalismo pois verificou-se que todas as aberturas sem exceção ou foram roubadas ou quando existentes estavam quebradas. O sistema elétrico foi furtado por completo e o sistema hidráulico está com a grande maioria dos componentes quebrados. A segunda manifestação patológica com maior ocorrência nesta fachada foi a presença de vegetação. Em seguida encontraram-se muitas regiões com incidência de fissuras especialmente nos elementos estruturais com destaque para a laje do $2^{\circ}$ pavimento. Ressalta-se que há exposição da edificação ao ambiente marinho e, portanto, estas propiciam a entrada de agentes agressivos como cloretos e favorecem a corrosão das armaduras.

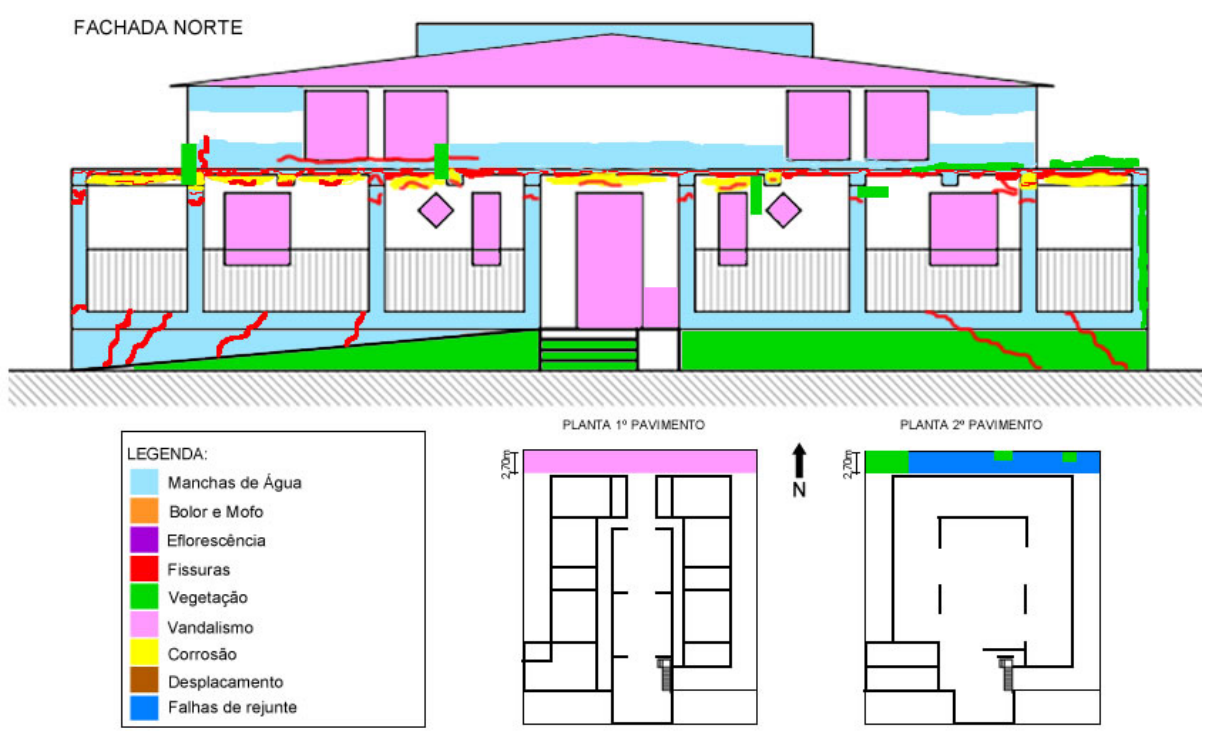

Figura 6: Mapa de danos - fachada norte

Em ordem de prioridade de intervenção de reparo, o total ponderado baseado na ferramenta de GUT para elementos avaliados na Fachada Norte a laje (2016 pontos) encontra-se em primeiro lugar, seguida da viga (1732 pontos) e do pilar (765 pontos). Este resultado já poderia ser previsto por conta da ausência de manutenções periódicas na edificação, a ocorrência de fissuras demonstrada no mapa de danos somada a agressividade do meio.

\subsubsection{Fachada leste}

A fachada leste foi dividida em 3 prumadas e seus elementos construtivos avaliados e destacados conforme a figura 7.

Para melhor compreensão das manifestações patológicas levantadas em campo e incidentes na fachada leste da edificação adotou-se o mapa de danos, conforme ilustra a figura 8. Sabendo-se que na fachada havia áreas cobertas por varanda, as manifestações patológicas identificadas nestas foram representadas em planta. Conforme a figura 8 nota-se que a manifestação patológica com maior área de abrangência na fachada leste se trata do vandalismo pois verificou-se que todas as aberturas sem exceção ou foram roubadas ou quando existentes estavam quebradas. O sistema elétrico foi furtado por completo e o sistema hidráulico está com a grande maioria dos componentes quebrados. A segunda manifestação patológica com maior ocorrência nesta fachada foi a presença de vegetação, bolor e mofo. No muro foram encontradas principalmente trepadeiras e no encontro dos pilares com a laje do $2^{\circ}$ pavimento mudas de pinheiro do tipo Casarina em crescimento. Em seguida encontraram-se muitas regiões com incidência de fissuras especialmente nos elementos estruturais com destaque para a laje do $2^{\circ}$ pavimento. 


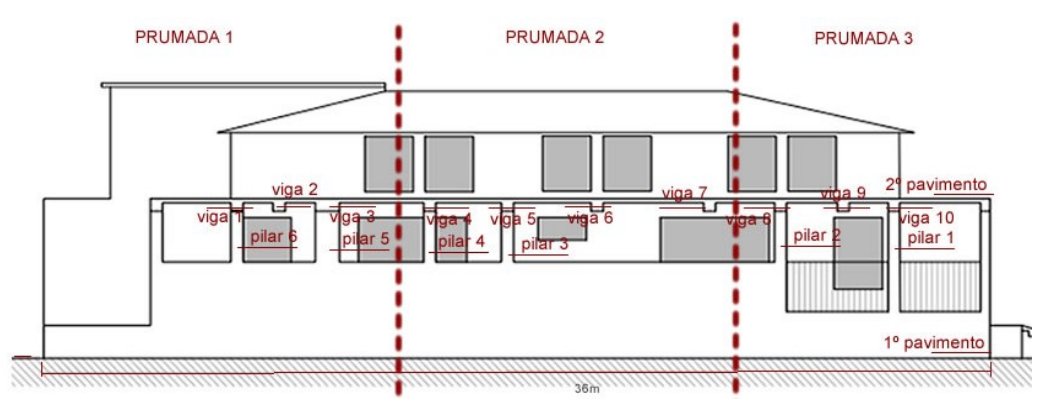

Figura 7: Fachada Leste, dividida em 3 prumadas

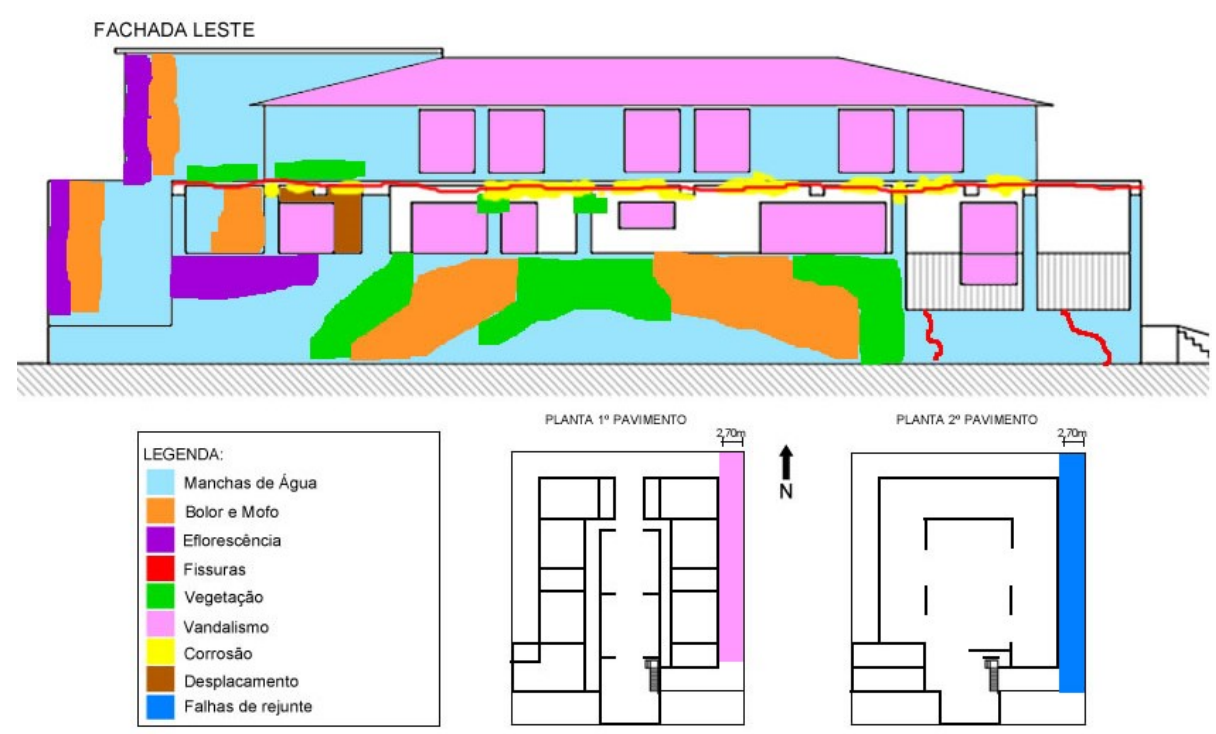

Figura 8: Mapa de danos - Fachada Leste

Em ordem de prioridade de intervenção de reparo, o total ponderado, baseado na ferramenta de GUT para elementos avaliados na Fachada Leste, a laje (2016 pontos) encontra-se em primeiro lugar, seguida da viga (1444 pontos) e do pilar (189 pontos). O resultado encontrado corrobora que a ocorrência de danos está associadas à ausência de manutenções periódicas na edificação, somada a agressividade do meio.

\subsubsection{Fachada sul}

A fachada sul foi dividida em 3 prumadas e seus elementos construtivos avaliados e destacados conforme a figura 9.

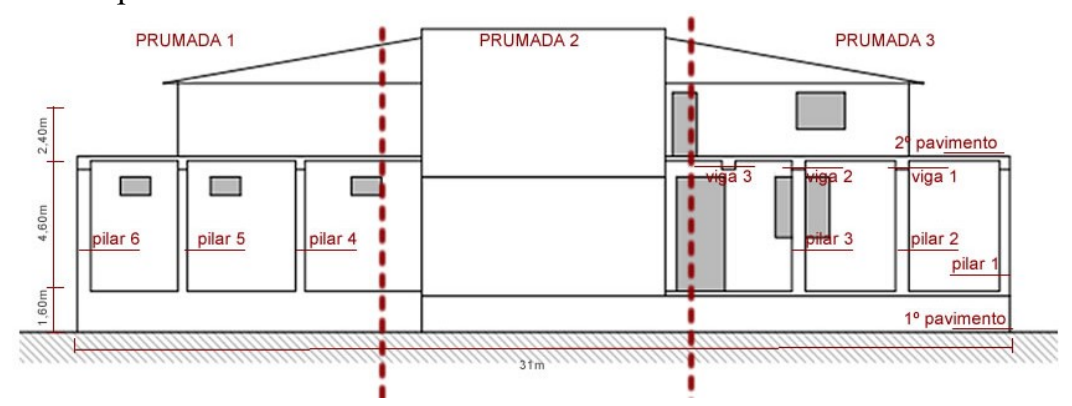

Figura 9: Fachada sul, dividida em 3 prumadas

Da mesma fora que nas fachadas anteriores adotou-se o mapa de danos, para apresentação das manifestações patológicas levantadas em campo e incidentes na fachada sul da edificação, conforme ilustra a figura 10. Sabendo-se que na fachada havia áreas cobertas por varanda, as manifestações patológicas identificadas nestas foram representadas em planta. Nota-se que a manifestação patológica com maior área de abrangência na fachada sul se trata do vandalismo pois verificou-se que todas as aberturas sem exceção ou foram roubadas ou quando existentes estavam quebradas. $\mathrm{O}$ sistema elétrico foi furtado por completo e o sistema hidráulico está com a grande maioria dos componentes quebrados. A segunda manifestação patológica com maior ocorrência nesta fachada foi a presença de vegetação. Na base da parede 
de alvenaria foram encontradas principalmente trepadeiras e, no encontro dos pilares com a laje do $2^{\circ}$ pavimento, mudas pinheiro do tipo Casarina, em crescimento. Em seguida, encontraram-se muitas regiões com incidência de fissuras especialmente nos elementos estruturais com destaque para a laje do $2^{\circ}$ pavimento

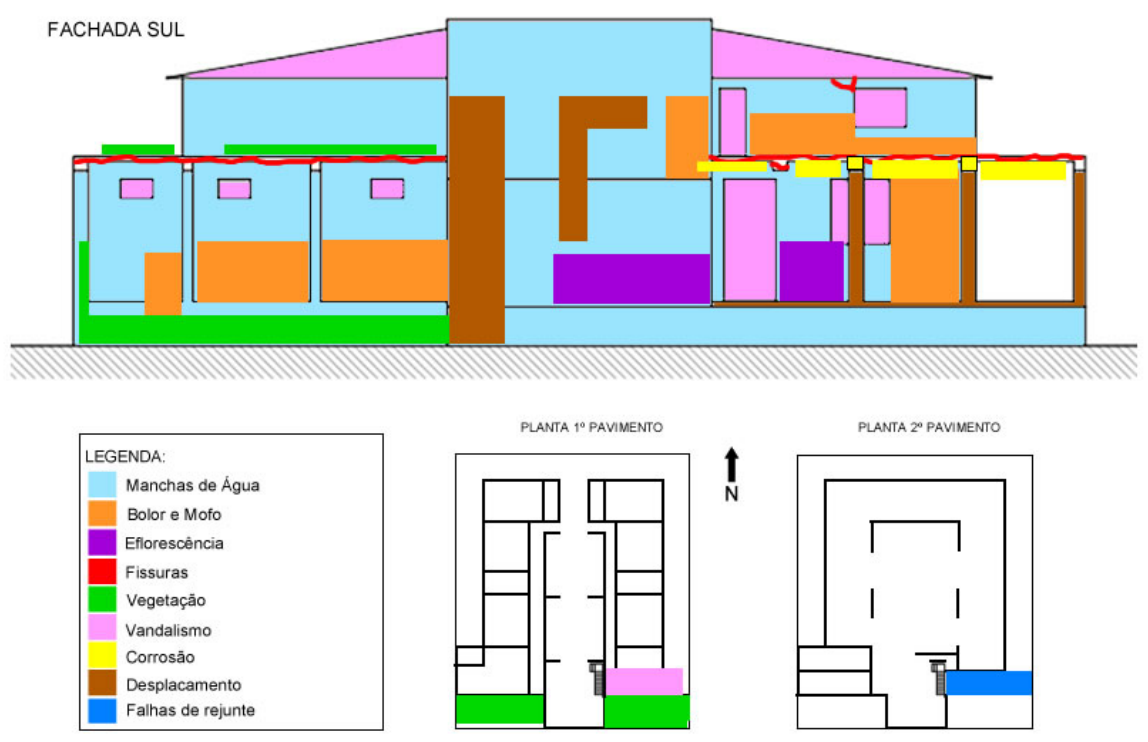

Figura 10: Mapa de danos - Fachada Sul

Em ordem de prioridade de intervenção de reparo, o total ponderado, baseado na ferramenta de GUT para elementos avaliados na Fachada Sul, a viga (854 pontos) encontra-se em primeiro lugar, seguida do pilar (792 pontos) e da laje (576 pontos). Mais uma vez a ausência de manutenções periódicas na edificação, somada à agressividade do meio demonstraram ser as principais razões para ocorrência de manifestações patológicas.

\subsubsection{Fachada oeste}

A fachada oeste foi dividida em 3 prumadas e seus elementos construtivos avaliados e destacados conforme a figura 11.

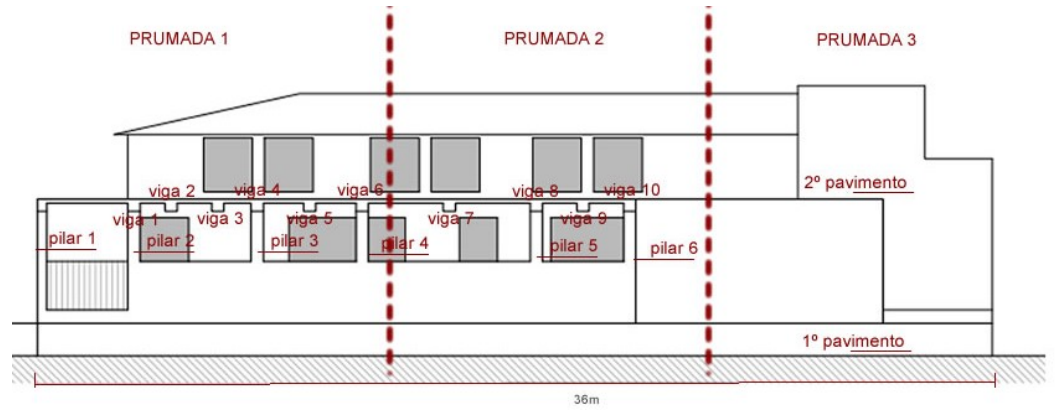

Figura 11: Fachada oeste, dividida em 3 prumadas

Assim como para as demais fachadas, as manifestações patológicas levantadas em campo e incidentes na fachada oeste da edificação foram apresentadas na forma de mapa de danos, conforme ilustra a figura 12. Sabendo-se que na fachada havia áreas cobertas por varanda, os danos identificados nestas foram representados em planta. A manifestação patológica com maior área de abrangência na fachada oeste se trata do vandalismo pois verificou-se que todas as aberturas sem exceção ou foram roubadas ou quando existentes estavam quebradas. O sistema elétrico foi furtado por completo e o sistema hidráulico está com a grande maioria dos componentes quebrados. A segunda manifestação patológica com maior ocorrência nesta fachada foi a presença de vegetação. Na base da parede de alvenaria foram encontradas principalmente trepadeiras e no encontro dos pilares com a laje do $2^{\circ}$ pavimento mudas de pinheiro do tipo Casarina em crescimento. Em seguida encontraram-se muitas regiões com incidência de fissuras especialmente nos elementos estruturais com destaque para a laje do $2^{\circ}$ pavimento.

Ressalta-se que há exposição da edificação ao ambiente marinho e, portanto, estas propiciam a entrada de agentes agressivos como sal e favorecem a corrosão das armaduras destes elementos. Em ordem de prioridade de intervenção de reparo, o total ponderado, baseado na ferramenta de GUT para elementos avaliados na Fachada Oeste, a laje (1494 
pontos) encontra-se em primeiro lugar, seguida da viga (584 pontos) e do pilar (273 pontos). O resultado verificado nesta fachada demonstra que a ausência de manutenções periódicas na edificação e a ocorrência de fissuras demonstrada no mapa de danos somada a agressividade do meio persistem como principais causas.

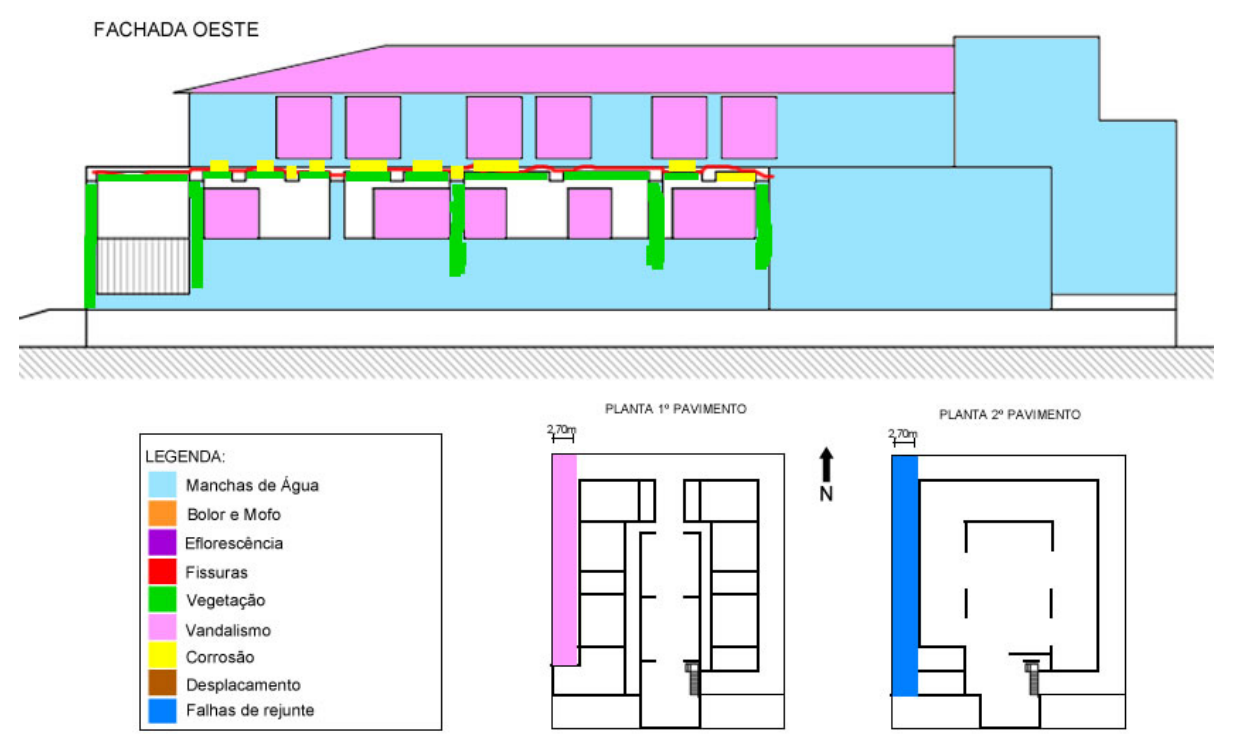

Figura 12: Mapa de danos - fachada oeste

\subsection{Análise geral de danos nas fachadas}

A partir da compilação dos dados coletados e registrados nas FIDs, foi possível avaliar de forma comparativa o estado de cada fachada da edificação inspecionada, como se observa na figura 13.

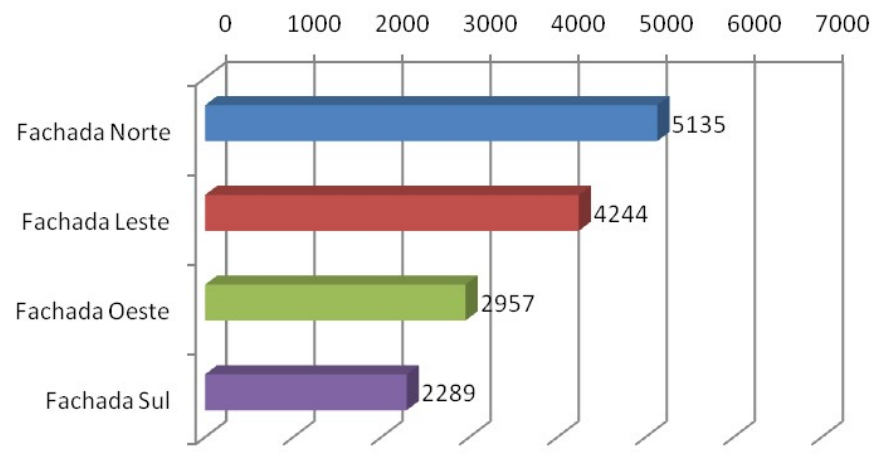

Figura 13: Ordem de prioridade de intervenção por fachada da edificação

Conforme se observa, a fachada norte apresenta maior quantidade de manifestações patológicas, tornando prioridade frente às outras fachadas da edificação. Há uma peculiaridade neste estudo de caso, pois a fachada sul, se encontra em melhores condições que as demais. Isso se atribui possivelmente à locação da edificação, visto que a fachada sul está voltada para o morro que faz uma barreira de proteção. Por outro lado, as fachadas leste e norte têm exposição direta ao mar. A deterioração da fachada oeste se deu em sua maioria pela grande presença de vegetação.

Analisando-se as possíveis causas do surgimento das manifestações patológicas conforme obtido no registro do mapa de danos e FIDs, a partir da figura 14, observou-se que a principal fonte de manifestação patológica foi o vandalismo, seguido da falta de manutenção e depois pela ação agressiva do meio ambiente (figura 15).

O vandalismo, mensurados em $60 \%$ do total das origens dos danos, prejudica o funcionamento do prédio, aumentando os custos de reparos significantemente. Seguem discriminados os elementos danificados por vândalos:

- Sistema elétrico - furtado por completo

- Sistema hidráulico - todos os componentes externos estão quebrados, incluindo torneiras, louças, registros, canos aparentes e caixas d'água. O sistema de motores de bombeamento de água foi furtado. 
- Aberturas - todas as aberturas estão danificadas, algumas completamente e outras parcialmente.

- Piso - a parte em que o piso é de madeira está avariado, quebrado com muitas partes ausentes.

- Pintura - todas as paredes possuem pichações.

- Cobertura - o telhado está comprometido por sua totalidade, todas as telhas apresentam rachaduras, furos e a grande maioria estão significativamente quebradas. As madeiras que compõem a estrutura do telhado, aproximadamente $10 \%$, estão quebradas e ausentes, o restante encontra-se em bom estado, porém expostas ao tempo sem nenhum tipo de tratamento, pois as telhas não exercem a sua função de estanqueidade.

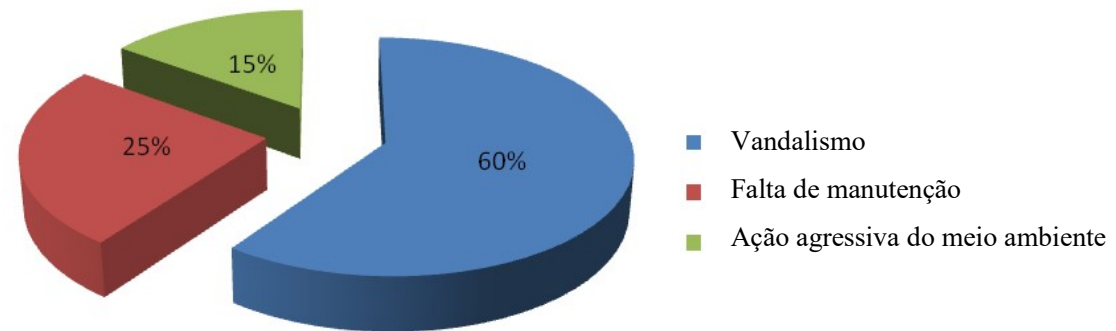

Figura 14: Principais origens das manifestações patológicas existentes

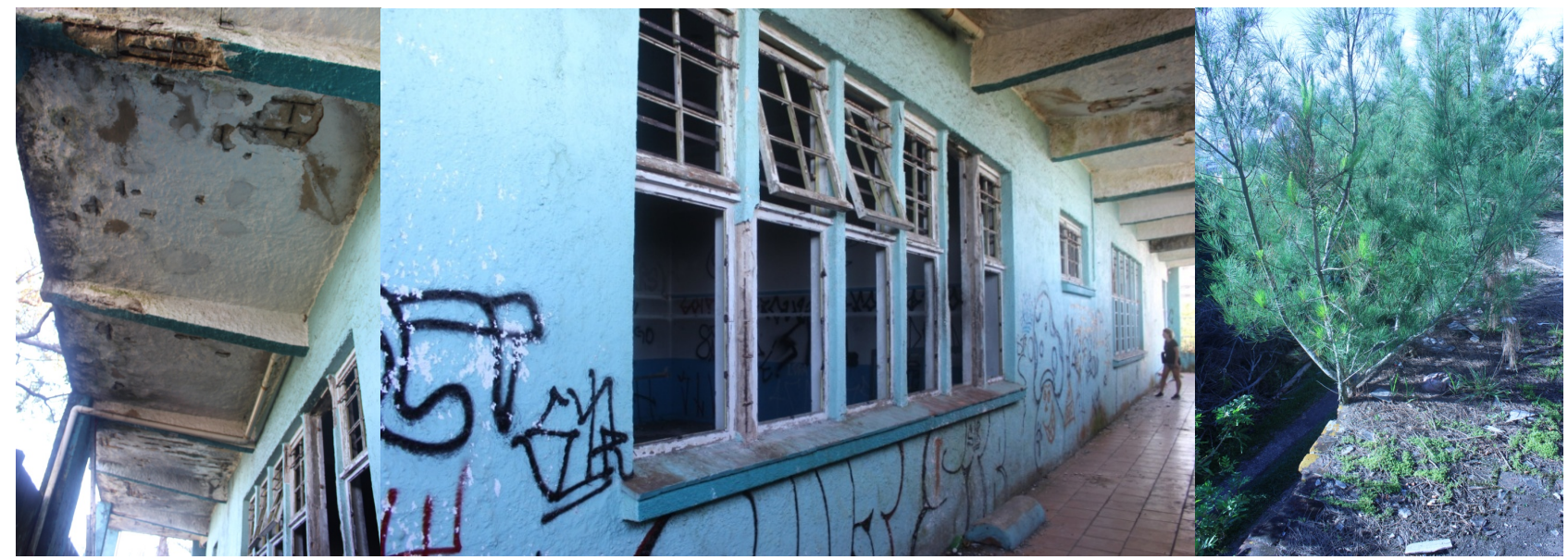

Figura 15: a) corrosão em lajes e vigas na área externa e vandalismo na fachada leste, b) vegetação na laje fachada oeste (Fonte: Autoria própria)

As falta de manutenção (25\%) e ação agressiva do meio ambiente (15\%) se correlacionam de uma forma geral na ocorrência de manifestações patológicas. Destaca-se a seguir os principais eventos encontrados:

- Falha no escoamento pluvial - As calhas e canos estão entupidos de folhas e areia, em muitos pontos encontram-se raízes em excesso. Os rufos estão descolados e não exercem a estanqueidade esperada.

- Vegetação - presente em todas as fachadas da edificação, destacando a fachada oeste, com trepadeiras e vegetação nativa nascendo nos pilares, muros e extremidades das lajes, principalmente nos pontos próximos aos dutos de escoamento pluvial.

- Manchas de umidade - em maior predominância na fachada sul, há manchas de umidade em todas as fachadas da edificação. Muitas dessas manchas provem da falta de detalhes arquitetônicos para expelir a água da fachada como as pingadeiras, também há manchas provenientes de infiltrações devido a fissuras nos elementos e falhas no escoamento pluvial.

- Infiltração - principalmente nas lajes externas, oriundas da ausência do rejunte do revestimento e falta de caimento para escoamento da água da chuva. Há infiltração em demais pontos devido à vegetação e fissuras.

- Fissuras - em toda a extensão da laje, registrou-se uma fissura devido à diferença da dilatação térmica do concreto utilizado na laje e o revestimento aplicado, essa fissura está exatamente localizada na camada de impermeabilização da laje. No topo do pilar registraram-se fissuras higroscópicas no revestimento.

- Corrosão - registrou-se corrosão nas vigas e na parte inferior das lajes, essa corrosão foi originada pela infiltração nos elementos construtivos e um possível ataque de cloretos

- Desplacamento - há desplacamento no revestimento dos pilares e alguns pontos das paredes da fachada sul, ocasionado devido à grande presença de umidade. Na laje há um desplacamento do revestimento superior, 
devido à ausência do rejunte e infiltração de água. Nas vigas há desplacamento nos casos de corrosão mais avançados.

\section{CONSIDERAÇÕES FINAIS}

Apesar da sua importância e do valor cultural para sociedade torrense a edificação escolar localizada no Morro do Farol em Torres - RS destinada ao uso da Escola Cenecista Prof. Durban Ferraz Ferreira, encontra-se abandonada há seis anos e apresenta diversas manifestações patológicas aparentes.

Com os critérios e metodologia aplicada na inspeção, a análise do mapa de danos e das FIDs mensurados com ponderador individual de cada elemento estrutural avaliado, foi possível verificar que os ponderadores eximem a edificação de risco de imediato colapso. Suas manifestações patológicas são de grande tendência e pode em curto espaço de tempo comprometer elementos estruturais fundamentais para segurança da edificação. A interpretação analítica do mapa de danos permitiu verificar que a edificação apresenta manifestações patológicas que provem principalmente do vandalismo, problemas em sua estanqueidade e um possível ataque de cloretos nos elementos de concreto armado da área externa e fachadas intensificados pela falta de manutenção e ação agressiva do meio ambiente. Observou-se que a edificação apresenta riscos aos vizinhos, devido à instabilidade da cobertura, e com um vendaval há possibilidade de voar telhas e atingir residências vizinhas, veículos, transeuntes e andarilhos que habitam a edificação.

De forma geral para uma edificação pública abandonada, sem rotinas de manutenção preventiva e corretiva especialmente expostas a condições de agressividade intensas como neste objeto de estudo, exposta ao ambiente marinho, estão mais sujeitas a alta incidência de manifestações patológicas e com o abandono estas podem evoluir levando a um possível colapso da edificação. Por fim, recomenda-se a interdição do local com atuação de imediato, com a retirada dos objetos soltos na cobertura, retirada das vegetações existentes nas estrutura e início de um projeto de restauração. Pretende-se através deste estudo de caso motivar a recuperação da edificação e seu retorno ao uso da comunidade.

\section{REFERÊNCIAS}

ASSOCIAÇÃO BRASILEIRA DE NORMAS TÉCNICAS. NBR 2011: Avaliação de bens - Parte 2: Imóveis urbanos. Rio de Janeiro, 1999.

AMERICAN SOCIETY FOR TESTING \& MATERIALS. ASTM E632-82: Standard Practice for Developing Accelerated Tests to Aid Prediction of the Service Life of Building Components and Materials. ASTM International, West Conshohocken, PA, 1982.

ANTUNeS, G. Estudo de Manifestações Patológicas em Revestimentos de Fachada em Brasília - Sistematização da Incidência de Casos. Dissertação de Mestrado - Universidade de Brasília. Distrito Federal, 2010.

FORTES, L. R. Corrosão na armadura do concreto armado e sua avaliação pela técnica do potencial de eletrodo. Fortaleza-CE, 1995. 244p. Dissertação (Mestrado). Universidade Federal do Ceará.

INSTITUTO BRASILEIRO DE AVALIAÇÕES E PERÍCIAS DE ENGENHARIA. Norma de Inspeção Predial do IBAPE Nacional, 2012.

KEPNER, C. H.; TREGOE, B. B. O administrador racional. São Paulo: Atlas, 1981

LERSH I. M.; Contribuição para identificação dos principais fatores e mecanismos de degradação em edificações do patrimônio cultural de PoaRS. Tese mestrado; UFRGS; Porto Alegre. 2003

NEUMANN, P. N. et al. Patologias nas edificações: uma nova concepção na contrução civil. Revista Interdisciplinar de Ensino, Pesquisa e Extensão v. 4, n. 1, 2017.

PACHECO, C.; VIEIRA, G. Metodologias para inspeções de fachadas de edifícios. Conferencia Nacional de Patologia e Recuperação de estrutura. COMPAR, Anais. 2017.

THOMAZ, E. Manual técnico de manutenção e recuperação. FDE. São Paulo, 1990

TINOCO, J. E. L. Mapa de danos: recomendações básicas. Textos para discussão - Série 2: Gestão de restauro. Centro de Estudos Avançados da Conservação Integrada, Anais. Olinda,2009.

TOMAZELI, A.; HELENE, P. Diretrizes para a inspeção, análise e aceitação de concreto em estruturas de edifícios habitacionais com obras paralisadas. In: Anais da Conferência Nacional de Patologia e Recuperação de Estruturas. 2017. 